\title{
TOTAL RESPONSIBILITY OF THE SURGEON IN THE MANAGEMENT OF TRAUMATIC SPINAL PARAPLEGICS AND TETRAPLEGICS
}

\author{
By Professor Sir Ludwig Guttmann, C.B.E., F.R.S., M.D., F.R.C.P., F.R.C.S. \\ Aylesbury, England
}

\begin{abstract}
Surgeons of whatever speciality concerned with the acute treatment of spinal cord injuries have to accept total and not fragmented responsibility in the management of these patients. This involves certain key responsibilities which are discussed in detail in the light of professional liabilities.
\end{abstract}

Key words: Professional liability; key responsibilities; fragmented management

IN his Nuffield Lecture 'Medicine at the Crossroads: Learned Profession or Technological Trade Union' (1976), Professor Sir George Pickering, late Regius Professor at Oxford University, made the following opening remarks: 'When I qualified as a doctor, medicine was at its best, deeply respected as a learned profession. The best doctors were learned, and the less good would have liked to be, and they respected those who were. Doctors as a group sought to maintain and enhance professional standards, etiquette and behaviour and discouraged those who erred or sought to err. Now medicine seems to be in danger of ceasing to value or respect learning. What would have been regarded as unprofessional behaviour is not only tolerated now but encouraged by the larger organisations of both senior and junior doctors. This is what I mean by Medicine at the Crossroads. In my more realistic and pessimistic moods, I suspect that we are no longer pausing at the crossroads, but that we have already crossed. And yet, the best of our young doctors are so good that if they are not ruined by the myopic selfishness of their predecessors or by the prejudiced stupidity of politicians and bureaucrats, I am sure that there is still hope'. This is indeed plain talking by one of the leading members of our profession.

I belong to the pre-Pickering generation, for when Pickering qualified as a physician in 1928, I happened to be already a neurological and neurosurgical specialist. I was then Neuro-surgeon at the Department of Psychiatry and Neurology of the University of Hamburg, Friedrichsberg, actually the only neurosurgeon in a Department of Psychiatry in Europe. I feel, therefore, that I am entitled to comment upon Pickering's sentiments expressed, and I cannot but share them from personal observations made throughout many years not only in Germany and England but during my visits to many other countries. We must not close our eyes to the lamentable fact that the noble Profession of Medicine has lost a good deal of its respect, admiration and reputation amongst the public in some countries. In this connection, it is significant that a recent statement made by the American Surgical Association (A.S.A.) on Professional Liability (1976) presents a frank analysis of the deplorable state of affairs prevailing in the United States with regard to both patients and surgeons, in which it is revealed that as a result of malpractice, insurance premiums for physicians and surgeons as well as hospitals may soon exceed two billion dollars a year. This statement of the distinguished Association of Surgery points out that there were twice as many malpractice suits in 1975 as in I970, and the average jury-trial award has increased 
sixfold. From personal observations in litigation cases, I know how enormous the jury-awards can be in the U.S.A. and they are also increasing in Great Britain. For instance, in a case of malpractice in a traumatic tetraplegia in U.S.A. the patient was awarded more than one million dollars. This was the case of a man with an incomplete tetraplegia below C6 spinal cord segment as a result of a fracturedislocation of the $\mathrm{C}_{5} / 6$ who, after admission to a hospital under the care of a neuro-surgeon, made a steady functional recovery. When he reached what is called 'a plateau' the surgeon advised the patient to have a laminectomy done because, as he put it, 'You would regret it later not to have had this operation'. What the surgeon ignored was the active infection of the urinary tract with raised temperatures from which the patient was suffering at that time, and the well known fact that any functional recovery following severe injury of the nervous system may be delayed and even temporarily stopped by an intervening infection if any part of the organism was overlooked or ignored. The patient and his wife reluctantly agreed to the surgeon's recommendation. Unfortunately, following the laminectomy where the neuro-surgeon on opening the dura had to confirm his previous diagnosis of a contusion of the cord at the site of the fracture, the patient became a complete tetraplegic. Although, in due course, he made again some functional improvement, because of inadequate after-care he developed contractures in the fingers of both hands which greatly interfered with the muscular recovery. It is now 28 years since in a paper on the surgical aspects of the treatment of traumatic paraplegia published in the Fournal of Bone E Foint Surgery (1949), I strongly opposed the views expressed by Haynes in the Am. Fournal of Surgery (1946) that exploration of the injured spinal cord is indicated even in the presence of neurological improvement if there is radiographic evidence of laminal damage. The relevant sentence in my paper reads as follows: 'There is no hurry whatsoever, and it is nearly always safe to wait at least until the progress of recovery has ceased'. In recent years numerous neuro-surgeons and orthopaedic surgeons have adopted this conservative approach. Naturally one has, as the cases just quoted shows, to consider more carefully whether or not the stoppage of recovery in incomplete cord injuries may be caused by intervening infections of any kind, before contemplating a major operation on the spine.

According to A.S.A.'s Statement on Professional Liability, it is at present estimated that regrettably only i 5 to 20 per cent of the money awarded by the court reaches the patient himself. The remainder is paid for court costs, plaintiff's lawyer contingent fees and expenses and the expense of the defence. According to the A.S.A. statement 40 to 50 per cent of judgment have been claimed by some lawyers. As the fee paid to the lawyer is proportioned to the size of settlement this naturally encourages claim and jury trials. The escalating expense of professional liability insurance consequently results in higher surgical fees and higher costs for all aspects of medical care.

In Britain, the excessive claims for damages made against surgeons, with the time consuming and costly legal processes often involving numerous defendants of insurances, is still relatively small as compared with other countries, in particular North America. However, even if there is a lower incidence in Great Britain and other countries, this is no cause for complacency as there is no evidence that the number of medical mishaps is any less frequent. Actually, the General Medical Council of Great Britain has published a booklet on Professional Conduct and Discpline in May 1977. In this booklet convictions and forms of professional misconduct which may lead to discplinary proceedings are published in detail. They include neglect or disregard of personal responsibilities to patients by doctors 
or surgeons concerned with the care and treatment of their patients, improper delegation of medical duties, abuse of privileges and misuse of professional skills. The A.S.A. recommends, amongst other proposals, the the whole system of civil legal liability should be reviewed, but it also calls for better control of practice and the need to discipline offenders, even by withdrawing licence to practice and compulsary re-education. This in, turn, may also lead to costly legal procedures. Thus, a vicious circle may be created.

In view of all that has been said as a background to the present unfortunate situation affecting the medical profession, the title of this paper today 'The Surgeon's Total Responsibility' may be appropriate. Such a paper was, perhaps, less difficult to present before the era of specialisation in surgery. But, today, in view of the many surgical specialities, distinct responsibilities have to be condsidered in almost every branch of surgery. I should like to confine myself to discussing some problems concerning the surgeon's total responsibility in the multi-disciprinary specialty of spinal cord paraplegia and tetraplegia where accident-surgeons-as well as neuro-orthopaedic-and urological surgeons are the specialists mainly engaged in the management of spinal cord injuries with special reference to the immediate and early as well as late management of these severely afflicted patients.

Naturally, common to all surgeons, whether general or specialised, is the strict adherence to the creed of the supreme law in medicine: 'Nil nocere', 'Do not do harm', as embodied in the relevant paragraph of the Hippocratic Oath: 'I will use treatment to help the sick according to my ability and judgement, but never with a view to injury or wrong-doing'. The horrifying story of the 'experiments' conducted by Nazi doctors on living victims during Hitler's extermination campaign in the second World War, documented in Micherlich's and Mielke's book 'The Death Doctors, has exposed to everyone once and for all the terrible consequences if this fundamental principle of medicine 'Do not harm' is misinterpreted or disregarded. Following World War II and the Nuremberg War Crimes Commision, the World Health Organisation set up a Commision in Paris in 1947. From all the deliberations resulted eventually the Declaration of Geneva in 1948, which is very similar to the Hippocratic Oath although of a more general nature. Amongst the various paragraphs the following may be quoted: 'The Health of my patient will be my first concern'. How then does the concept of health of the spinal cord paralysed patient apply to our everyday work in the immediate and early management of traumatic paraplegics and tetraplegics?

Many specialists engaged in the immediate and early management of these acutely ill and most severely disabled patients are confused as to how their responsibility extends to these unfortunate victims of accidents in war and peace, whose health is instantaneously shattered. For they are deprived not of one but of a multitude of vital functions of the whole organism, resulting in complications such as ascending infection of the paralysed bladder and septic absorption from pressure sores, which are the main causes of chronic invalidism and death and which throughout centuries were considered by most members of the medical profession as inevitable. This is, no doubt to a great deal, caused by the hitherto prevailing fragmentation of management between the specialties concerned with these acutely ill patients, who feel that their responsibility is confined to the aspects of spinal cord injuries concerned with their own specialty. The confusion is further increased as the surgeon's responsibilities are divided between his paralysed patients and his patients with other afflictions of their own individual specialties. This applies in particular, to traumatic surgeons, neuro-surgeons and orthopaedic surgeons. Many of these surgical specialists as a rule still continue the philosophy 
practised by surgeons throughout centuries, that their concern is the treatment of the fractured spine and the damage of the spinal cord, while the care of the paralysis of the bladder, intestines, respiratory dysfunction and distress as well as the loss of vasomotor function takes second place or is not considered as of equal responsibility or even neglected. Otherwise paraplegics and tetraplegics would not arrive with the most severe complications on transfer to a spinal centre or rehabilitation unit following major surgical procedures. It has been claimed that by immediate stabilisation of the broken spine by fusions the duration of the patient's stay in hospital is considerably shortened. This is a myth, for the high costs of treatment and care in convalescent or rehabilitation departments have still to be paid by the patient, his relatives or the insurance for a considerable time, especially if the patient is transferred to these units with complications he has developed in the surgical departments. Naturally, if the traumatic paraplegic or tetraplegic could be admitted immediately to a Spinal Injuries Centre, as has been established successfully for many years in Great Britain and other countries, where a comprehensive management of all aspects of spinal cord injuries can be provided from the start and throughout all stages by a specialist team of workers, this would greatly facilitate the whole problem of responsibility. For the main, if not the total, responsibility lies squarely on the shoulders of the specialist in charge of the Spinal Centre who, as the co-ordinator of all aspects of the management of these patients, has the total responsibility for his patients. This was successfully achieved during and after World War II at the National Spinal Injuries Centre of Stoke Mandeville Hospital in Aylesbury and other spinal units in England. Unfortunately, this ideal has not yet been universally reached, the more so as circumstances not infrequently arise which make it imperative to admit spinal cord injured patients first to the Emergency Room of the accident unit of the nearest General Hospital.

\section{Key Responsibilities}

I should like now to discuss those problems where I believe any surgeon concerned with the immediate and early management of the spinal cord injured patient has key responsibilities.

The first key responsibility of a surgeon in this multi-disciplinary problem of spinal paraplegia and tetraplegia is, of course, his competence to deal with the many aspects of this affliction. It cannot be over-emphasised that this applies by no means just to his competence in dealing adequately with the diagnosis and technical management of the various types of vertebral fractures and dislocations and associated injuries to other parts of the skeletal system, as well as with the diagnosis and management of the resulting damage to the spinal cord, but also to his responsibility in dealing with the whole of the seriously ill human being. The surgeon must be aware that spinal cord injuries with their multifarious symptomatology as a result of the sudden interurption of vital functions are always potential risks even without additional injuries to other parts of the organism which, however, not infrequently occur and add to the risks. In this respect, competence also applies to a critical and highly discriminative approach to the techniques of surgical procedures, in particular skull traction, laminectomy and stabilising procedures by fusions, so that he can carry out his total responsibility to his patients without doing harm. However, competence applies equally to the prevention of the various complications resulting from severe spinal cord injuries, such as infection of the paralysed bladder and the development of pressure sores, and in cord lesions above the 5 th thoracic segment, especially in traumatic tetraplegia, in dealing adequately 
with the crippled vasomotor control resulting in thrombosis and hypotension on the one hand and automatic hyperreflexia on the other. Furthermore, his competence extends also to proper handling of the intestinal and respiratory paralysis, especially in cervical injuries.

The indiscriminate insertion of an indwelling catheter immediately into the paralysed bladder during the acute stage of spinal cord injury should be considered as much a mismanagement as previously a suprapubic cystostomy or Lapides' vesicostomy. For, it has been proved beyond all shadow of doubt that early infection of the paralysed bladder in spinal cord injured patients can be avoided by the 'non-touch' technique of intermittent catheterisation (Guttmann, I949, I976; Guttmann \& Frankel, I966). This gives the natural forces of repair in the organism an infinitely better chance of coping with the repair of fractures of the spine and other parts of the skeletal and motor system, as well as with the cord damage itself, than if these forces are interfered with and are inhibited or weakened by the additional strain of combating infection of the urinary tract. I hope in the future the argument or excuse so often made-'We haven't got the staff to do the proper intermittent catheterisation of the paralysed bladder'-will not be found acceptable if it came to litigation procedures. Nor should it be acceptable that orthopaedic and neuro-surgeons still advocate the indwelling catheter in the paralysed bladder in the acute stage of spinal cord injury, because no 'intermittent catheterisation team is available'. Intermittent catheterisation by the 'non-touch' technique as an emergency method in the management of the acutely paralysed bladder for preventing early infection of the urinary tract should be part of the armamentarium of every surgeon or physician concerned with the management of acute spinal cord injuries, with which he has to be as familiar as he has with other procedures of management of the acutely ill patient.

The same, of course, applies to the competence in preventing pressure sores developing in the acute and early stages, for which the surgeon himself has the key responsibility and not, as often claimed, the nursing staff. It has been proved beyond any shadow of doubt that pressure sores, which for centuries were considered an inevitable complication of spinal cord injuries, can be prevented even in the most seriously afflicted patients, such as cervical injuries even associated with other injuries to the organism.

A further key responsibility of a surgeon concerned with the management of spinal cord injuries is proper and detailed documentation of the history and symptomatology of the patient from the start, and especially the importance of the detailed documentation of the initial findings cannot be overstressed. In this respect I have often been disappointed and greatly concerned about the scanty and superficial documentation of the first clinical examinations written by the medical staff of the Emergency Room, which in litigation cases have been used by lawyers to the surgeon's disadvantage. The clinical records should register not only details of the patient's history including details of the accident (wearing of seat belt, signs of drunkenness, lost memory, state of consciousness, type of first aid management) but above all full details of the first neurological examination in addition to the cardiovascular and respiratory status. The result of the first neurological examination should include precise statements of the function of individual muscles, especially of the upper limbs in cervical injuries, and of the muscles of the lower limbs in conus-cauda equina lesions as well as reflexes, including bulbo-cavernosus and anal reflexes, furthermore details of the disturbances of sensory function including the presence or absence of sacral sparing as well as function of the bladder and other autonomic mechanisms such as bowel sounds, respiration, penile 
engorgement or priapism. The neurological examination should be repeated before and after the first therapeutic measures such as postural reduction, skull or halter or halo traction and later in the intensive care unit, once the patient has recovered or is recovering from the traumatic shock or unconsciousness which may accompany spinal cord injuries. In tetraplegics it is quite unsatisfactory to register 'paraplegia of the lower limbs and "partial" paralysis of the upper extremities' without giving details of the function of the individual muscles in both complete and incomplete cervical lesions. These initial findings are most essential for control examinations following the first therapeutic procedure, in particular skull traction, fusions or laminectomy, halotraction and postural reduction.

As a rule, spinal cord casualites are first seen in the Emergency Room by surgical registrars or residents or general surgeons with limired knowledge of neurology and, moreover, limited experience (if any) in dealing with this multidisciplinary problem of spinal cord injuries. Therefore, the first examiner's key responsibility is to recognise his own competence or limitations in dealing adequately with the diagnostic and initial therapeutic procedures, especially in cervical injuries. In view of the complexity of symptomatology in the great majority of spinal cord injuries, any delay in calling immediate consultation with a neuro-surgical or orthopaedic specialist may lead to disastrous consequences.

This brings me to the problem of the initial X-ray examination of spinal cord injuries, especially following fractures of the cervical spine. It is a further key responsibility of the surgeon of whatever specialty to supervise personally the X-ray examination if either performed by a transportable X-ray machine or following transport of the patient to the X-ray department whenever this becomes necessary, and the greatest care has to be taken to avoid movements of the patient, especially of the head in semi-conscious, restless and unco-operative patients with suspicion of a cervical fracture. The head should be properly supported even in patients admitted without or with minimal neurological symptoms, for instance following head injuries suffering from cerebral concussion.

As a radiologist is not always available in the early hours of the morning the radiographer should be thoroughly informed and supervised by the surgeon or medical officer about details of the X-ray examination. It is of utmost importance to ask for both lateral as well as a-p X-rays. While, as a rule, the lateral X-ray will reveal the nature of the fracture on fracture-dislocation, there are incidences where the lateral X-ray just shows what appears to be a simple compression wedge fracture while the real nature of damaged articulations is revealed by the a-p X-ray, suggesting instability of the broken vertebra. Another default at the first X-ray examination is the failure of demonstrating all vertebrae of the cervical spine in the lateral X-rays as a result of insufficient downwards pull of the arms. To what unfortunate consequences mismanagement in the X-ray examination may lead is shown by the following case: A female student, aged I6, while a pillion rider on a motor bycicle, was involved in an accident in I97I at about I a.m. in which the driver was killed. She was admitted to the Emergency Room of a hospital where she was seen by a Board Certified Surgeon I hour later. The physical examination was as follows: The girl was in acute stress, B.P. 70/50, pulse thready at 100, respiration $\mathrm{I} 4$. There was a large scalp laceration over the parietal lobe, eyes were rolled up and to the left, the patient being semi-conscious and restless. There was tenderness of the supra-clavicular muscles but motion of the head was free and she moved all extremities well including upper limbs. Abdomen soft. Deep tendon reflexes were normal and there were no abnormal reflexes. Because the renal output ceased 'somewhat' for several hours, the general surgeon, specialising also 
in vascular surgery, performed a flash renal arteriogram which, however, showed no injury to either kidney. His assumption of an occlusion to the renal artery was not confirmed.

The first X-ray of the cervical spine in the lateral view revealed a simple fracture of the anterior portion of the 5 th cervical verterbra. The a-p X-ray, however, showed dislocation of the articulations of $\mathrm{C}_{5}$ which was overlooked. The patient, although restless and moving about, was transferred with the head supported only with sandbags. When an X-ray was taken later in the I.C.U. it revealed, in contrast to the first X-ray in the Emergency Room, a profound posterior displacement of the whole body of the 5 th cervical vertebra into the spinal canal. The girl developed a complete tetraplegia afterwards which was discovered only the next morning, first by the night nurse at $6 \mathrm{a} . \mathrm{m}$. and then confirmed by the surgeon at 7 a.m., who only then got in touch with a neuro-surgical department of another hospital, and the patient was transferred, again with sandbags only as support. At the neuro-surgical unit of the other hospital, head traction was immediately carried out followed by a decompresive laminectomy between C4-C6. This operation had no beneficial effect whatsoever, actually it only resulted in increased instability of the cervical spine in anterior flexion necessitating a further operation later for an anterior fusion to stabilize the broken spine. An X-ray taken 5 days after the fusion showed that the body of $\mathrm{C}_{5}$ vertebra was destroyed to insert the bone graft which, however, became displaced anteriorly between $\mathrm{C}_{5}$ and C6 and the angulation of the spine was increased. Therefore, the girl had to undergo a further operation and a fusion between $\mathrm{C} 6$ and $\mathrm{C}_{7}$ by a metal screw through the body of C6 was performed. The previously inserted bone graft was no longer visible.

This case shows dramatically the tragic consequence of an initially incompetent handling of a young girl with cervical fracture without neurological signs, but deteriorating by mismanagement into a complete permanent tetraplegia consequently necessitating three major though unsuccessful operations. Naturally, litigation procedures are pending.

Finally, there is a further key responsibility of a surgeon, namely to give proper and, if desired by the patient or his relatives detailed information to the patient's relatives about the patient's condition and the proposed surgical procedure. In view of the frequency and increase of compensation claims following major operations in recent years, it is in the surgeons' personal interest to be circumspect when suggesting immediate major operations as 'emergency' measures, such as laminectomy or stabilising operations by fusions. Alternative procedures should be mentioned, especially in incomplete cervical injuries, such as a skull traction or conservative measures such as halo-traction, to give the relatives time to think and to weigh up the risks and to take then their responsibility in deciding an emergency treatment or to ask for another opinion. I have found that in cases of unsuccessful major operations, relatives or patients themselves although having signed the usual form of consent, have complained about insufficient information on the part of the surgeon in charge, which naturally was taken up by the plaintiff's lawyer in the litigation case.

\section{SUMMARY}

Summarising all the observations reported here in the light of professional legal liabilities, which can be greatly amplified, it is obvious that any surgeon confronted with the immediate and early treatment of spinal cord injuries has to accept the total responsibility and not a fragmented one. There are certain key 
responsibilities in the management of this multi-disciplinary subject if medicine which are indispensable for the health of those afflicted with severe spinal cord injuries whose health is suddenly shattered and body and soul thrown into chaos. The many problems involved demand comprehensive understanding and constant vigilance and circumspection in all details of management, which will obviate or at least diminish serious consequences of legal procedures later. As long as the fragmentation between immediate, early and long-term management survives, teamwork in this multi-disciplinary subject should not be confined to the surgeons involved but must include a priori the man who will have the task of carrying out all measures of rehabilitation later.

\section{RÉSUMÉ}

Si l'on résume toutes les observations données ici à la lumière des responsabilités professionnelles, qui peuvent être très étendues, il est évident que tout chirurgien confronté au traitement immédiat er précoce de lésions de la moelle épinière doit accepter la responsabilité totale et non une responsabilité partielle.

Dans le traitement de ce sujet multidisciplinaire de la médecine, il existe certaines responsabilités essentielles indispensables a la santé de ceux qui sont affligés de graves lésions de la moelle épinière et dont la santé est soudain détruite et qui sont physiquement et moralement ébranlés. Les nombreux problèmes qui se posent exigent une compréhension complète et une vigilance constante, de même que l'attention à tous les aspects du traitement, ce qui permettra d'éviter ou en tout cas de réduire les conséquences graves des procédures juridiques ultérieures.

Aussi longtemps que dure la fragmentation entre traitment immédiat, précoce et à long-terme, le travail en équipe dans ce domaine multidisciplinaire ne doit pas se limiter aux chirurgiens concernés, mais il doit comprendre a priori l'homme qui sera chargé de mettre en oeuvre toutes les mesures destinées plus tard à la réadaption.

\section{ZUSAMMENFASSUNG}

Aus allen Beobachtungen über professionelle Haftpflicht ergibt sich die Notwendigkeit für jeden Chirurgen, der mit der akuten Behandlung von Rückenmarkverletzungen betraut ist, eine totale Verantwortung für alle Probleme zu übernehmen. Es gibt hierbei gewisse Haupt-Responsibilitäten, die in dieser multi-disziplinären Spezialität unerlässlich sind. Die vielen Probleme der Rückenmark-veletzung verlangen volles Verständnis, dauernde Wachsamkeit und Vorsicht in allen Einzelheiten der Behandlung, was ernste Konsequenzen von spaeteren Rechtsansprüchen verhinlern oder zum mindesten vermindern wird.

Solange noch die Fragmentierung zwischen der akulen, frühen und späten Behandlung besteht, Teamarbeit in dieser multi-disziplinären Spezialität sollte sich nicht nur auf die betreffenden Chirurgen allein beschränken sondern muss von vornherein den Arzt einschliessen, der für die spätere Rehabilitation des Gelähmten verantwortlich ist.

\section{REFERENCES}

American Surgical Association. (1976). Statement on professional liability. The New England Fournal of Medicine, 295, I292

General Medical Council, Great Britain. (1977). Professional Conduct and Discipline. William Cliver \& Sons, Colchester.

Guttmann, L. (1949). Surgical aspects of the treatment of traumatic paraplegia. F. Bone foint Surg. 3IB, 399.

Guttmann, L. (1949). Management of Paralysis. Brit. Surg. Tract, 6, 455.

Gutrmann, L. (1976). Spinal Cord Injuries, Comprehensive Management and Research (Second Edition ), p. 376. Blackwell Scientific Publications, Oxford.

GutTMANN, L. \& FRANKeL, H. (1966). The value of intermittent catheterisation in early management of traumatic paraplegia and tetraplegia. Paraplegia, 4, 63.

Haynes, W. G. (1946). Am. F. Surg. 72, 42.

Micherlich, A. \& Mielke, F. (I962). The Death Doctors. Elek Books, London.

PICKERING, SIR. G. (I977). Medicine at the crossroads: learned profession or technological trades union. Proc. Royal Soc. Med. 70, I6. 